\begin{tabular}{|c|c|}
\hline \multicolumn{2}{|c}{ Flatness Based Control of a HVAC System } \\
\hline Received 201\%/03/03 & Accepted after revision 2017/10/31 \\
\hline
\end{tabular}

\title{
Flatness Based Control of a HVAC System
}

\section{Arvo Kaldmäe, Ülle Kotta}

Department of Software Science, Tallinn University of Technology, Akadeemia tee 21, 12618 Tallinn, Estonia e-mail:arvo@cc.ioc.ee,kotta@cc.ioc.ee

Corresponding author: arvo@cc.ioc.ee

This paper studies the flatness-based control of a nonlinear multi-input multi-output heating, ventilating and air conditioning (HVAC) system. First, a novel method for checking flatness property is used to verify that the given HVAC model is flat and that the flat outputs are the temperature and the humidity ratio of the thermal space. Since the flat outputs are also the variables, which one usually wants to control, it is relatively easy to construct a flatness-based feedforward control for the HVAC model. We define the appropriate trajectories for the flat outputs and then the controller is computed from the parametrization of system inputs in terms of flat outputs and their derivatives. The trajectories of flat outputs are chosen such that the temperature and the humidity ratio converge asymptotically from the initial values to the desired values. Simulations are made, which show the effectiveness of the approach.

KEYWORDS: Control systems, flatness, HVAC system, nonlinear systems, MIMO systems.

\section{Introduction}

Heating, ventilating and air conditioning (HVAC) systems are used to control the temperature and humidity ratio in buildings to offer more comfortable environment to the occupants. HVAC systems are also large energy consumers and thus improvements to classical techniques such as ON/OFF and PID controllers, which are not energy efficient, are necessary. Popular methods like PID control, LQR control etc. require linear models or linear approximations, but intrinsically HVAC systems are nonlinear [3, 21]. Dif- ferent control approaches have been used to achieve energy efficient control, but at the same time ensuring occupant comfort. For example, robust control [1], intelligent methods like neural networks [8], model predictive control (see [16] and references therein), adaptive control $[5,11]$.

In [3] a nonlinear multi-input multi-output HVAC model was described, which has been studied a lot since then. In [3] an observer is constructed to estimate the states and also the thermal loads, which are 
viewed as system disturbances. After this a linear control law is designed, which also takes into consideration the estimates of thermal loads. In [17], a nonlinear controller is designed. First a nonlinear decoupling control scheme is developed to decouple temperature and relative humidity of thermal space. Then an outer-loop controller (a PD controller) is used for stabilization and control. The paper [5] applies the dynamic state feedback linearization techniques, after which the linearized system is controlled. Also, they design an adaptive controller to cope with the slowly time varying unknown thermal loads. Additionally, in [5] a switching mechanism is integrated to the system to keep the $\mathrm{CO}_{2}$-concentration in the system low. In the paper [18] the model is extended by adding valve dynamics and then it is partially linearized by static state feedback and state transformation. After linearization, as in [3], an observer is constructed to estimate the thermal loads and finally, a backstepping method is used to control the model. Lastly, in [12] the model is extended once more by adding dynamics to be able to regulate additionally the $\mathrm{CO}_{2}$ concentration in the thermal space. Then the extended model is linearized by dynamic state feedback and an extended state transformation. The linearized system is controlled by design of pole placement control and linear quadratic regulator, which also minimizes the cost function, which represents the performance characteristic requirements as well as the controller input limitations. In [11] a different approach is used. Namely, an adaptive control is used to control the given HVAC model.

In this paper, first, we show that the model, given in [3], is flat with flat outputs being the temperature and the humidity ratio of the thermal space. Since flatness property allows to parametrize all the system trajectories by the flat outputs and a finite number of their derivatives, by specifying the trajectories for flat outputs, one can compute the inputs needed for the flat outputs to follow the chosen trajectories from the trajectories of the flat outputs and their derivatives without solving any differential equations. We choose the trajectories for the flat outputs (i.e., for the temperature and the humidity ratio of the thermal space) such that they converge asymptotically from the initial values to the desired values. Then the feedforward controller can be directly computed from the parametrization of system inputs in terms of flat outputs and their derivatives. This is the standard flatness based control design, see $[9,10,14,20]$. Our feedforward controller depends only on the initial values, the desired values of the temperature and humidity ratio of thermal space and on the selected trajectories. Thus, one does not need to measure or estimate the system states, unlike in $[3,17,5,18,12]$, where state feedback is used to either control the model or linearize the system equations before applying the controller for stabilization and control purposes. The downside of our feedforward controller (and flatness-based control in general) is that it does not react to possible disturbances or modeling errors and thus the disturbances have to be included in the model and estimated or measured. In fact the same problem appears in the papers $[17,5,18,12]$, where the feedback linearization is used.

The results of this paper are remotely related to conference paper [4], where analysis of two HVAC models were performed. It was shown that the model, considered also in this paper, is accessible and the dynamic state feedback was computed, together with extended state transformation, to linearize the model. The paper is organized as follows. In Section II the flatness property is introduced and some preliminary results on flatness are given. Also, the mathematical approach used to check flatness is described. The main results are described in Section III. First, the HVAC model is described and its flat outputs computed. Then, the feedforward controller is found. In Section IV we describe the simulation results and the paper ends with some conclusions.

\section{Preliminaries}

Consider a continuous-time system described as

$\dot{x}=f(x, u)$,

where $x(t): \mathbb{R} \rightarrow \chi \subset \mathbb{R}^{n}$ is the vector of state variables, $u(t): \mathbb{R} \rightarrow U \subset \mathbb{R}^{m}$ is the vector of input signals and $f: \mathcal{X} \times \mathcal{U} \rightarrow \mathcal{X}$ is real analytic function.

Below we briefly recall from [6] the algebraic formalism, which we use to describe the flatness property and to compute the flat outputs. Let $\mathcal{K}$ denote the field of meromorphic functions in finite number of the in- 
dependent system variables, i.e., $\left\{x, u^{(k)}, k \geq 0\right\}$.Then, the pair $(\mathcal{K}, \mathrm{d} / \mathrm{d} t)$ is the differential field, which usually is denoted simply by $\mathcal{K}$. Over the differential field $\mathcal{K}$ one can define a vector space $\mathcal{E}:=\operatorname{span}_{\mathcal{K}}\{\mathrm{d} \varphi \mid \varphi \in \mathcal{K}\}$ spanned by the differentials of the elements from $\mathcal{K}$.

Define for system (1) the non-increasing sequence $\mathcal{H}_{k}$ of subspaces of $\varepsilon$ as follows $[2,6]$

$$
\begin{aligned}
& \mathcal{H}_{0}=\operatorname{span}_{\mathcal{K}}\{\mathrm{d} x, \mathrm{~d} u\} \\
& \mathcal{H}_{k}=\left\{\omega \in \mathcal{H}_{k-1} \mid \dot{\omega} \in \mathcal{H}_{k-1}\right\}, \quad k \geq 1 .
\end{aligned}
$$

The sequence converges after a finite number of steps, i.e., there exists $k_{*} \in \mathbb{N}$ such that $\mathcal{H}_{k_{*}}=\mathcal{H}_{k_{*}+1}$. Then we define $\mathcal{H}_{\infty}:=\mathcal{H}_{k_{*}}$. These subspaces play an important role in the study of flatness property of system (1), which is shortly discussed next.

\subsection{Flatness}

Flatness is a system property which is defined as existence of functions $y=h\left(x, u, \dot{u}, \ldots, u^{(r)}\right), y \in \mathbb{R}^{m}$, such that $x$ and $u$ can be expressed as functions of $y$ and a finite number of the derivatives of $y$ :

$$
\begin{aligned}
& x=F_{x}\left(y, \dot{y}, \ldots, y^{(k-1)}\right) \\
& u=F_{u}\left(y, \dot{y}, \ldots, y^{(k)}\right) .
\end{aligned}
$$

It is well known, see for example [10], that for continuous-time systems the flatness property is equivalent to the possibility to linearize an accessible system by a dynamic state feedback

$$
\begin{aligned}
& \dot{\eta}=\beta(x, \eta, v) \\
& u=\alpha(x, \eta, v)
\end{aligned}
$$

and an extended state transformation $\xi=\phi(x, \eta)$.

Next we recall some special cases from [2], which are valid for control-affine systems.

Theorem 1. System (1) is linearizable by the static statefeedback (i.e., by the feedback (4) where dim $\eta=0$ ) if and only if all the subspaces $\mathcal{H}_{k}$ are integrable and $\mathcal{H}_{\infty}=\{0\}$.

Theorem 2. System (1) with $m=n-1$ inputs is linearizable by dynamic state feedback (or equivalently, is flat) if and only if $\mathcal{H}_{\infty}=\{0\}$.

Theorem 2 states that any accessible nonlinear system with one less input than states is flat.

\section{Flatness Based Control of HVAC System}

\subsection{Model}

The model of the HVAC system is taken from $[3,17]$ and described in Fig. 1.

The differential equations describing the dynamics of the HVAC system can be derived from energy conservation principles as follows [3]

\section{Figure 1}

The model of the HVAC system

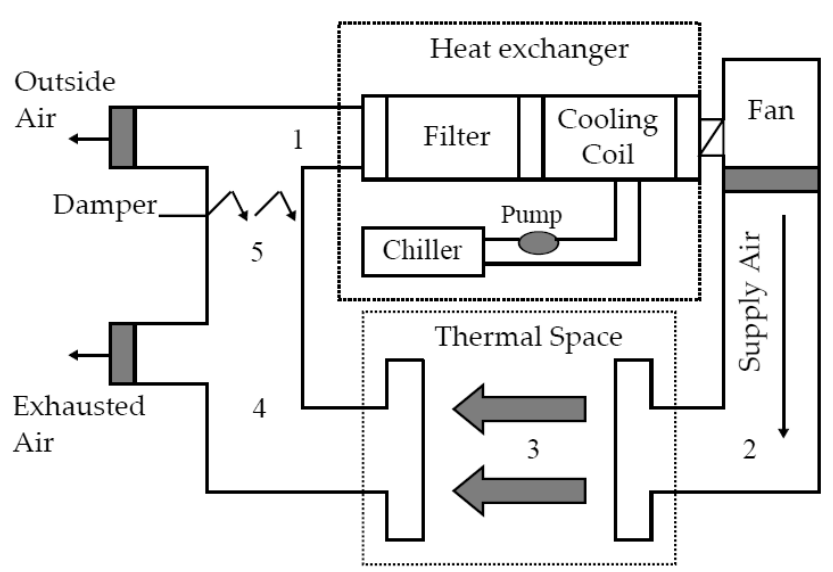




$$
\begin{aligned}
\dot{x}_{1}= & 60 \alpha_{1} u_{1}\left(x_{3}-x_{1}\right)-60 \alpha_{2} u_{1}\left(W_{s}-x_{2}\right) \\
& +\alpha_{3}\left(Q_{o}-h_{f g} M_{o}\right) \\
\dot{x}_{2}= & 60 \alpha_{1} u_{1}\left(W_{s}-x_{2}\right)+\alpha_{4} M_{o} \\
\dot{x}_{3}= & 60 \beta_{1} u_{1}\left(x_{1}-x_{3}\right)+15 \beta_{1} u_{1}\left(T_{o}-x_{1}\right) \\
& -60 \beta_{3} u_{1}\left(0.25 W_{o}+0.75 x_{2}-W_{s}\right)-6000 \beta_{2} u_{2}
\end{aligned}
$$

where $\alpha_{1}=1 / V_{s}, \alpha_{2}=h_{f g} / C_{p} V_{s}, \alpha_{3}=1 / \rho C_{p} V_{s}, \alpha_{4}=1 / \rho V_{s}$, $\beta_{1}=1 / V_{h e}, \beta_{2}=1 / \rho C_{p} V_{h e}, \beta_{3}=h_{w} / C_{p} V_{h e}$ and the physical meaning of variables and parameters is listed in Table 1.

\subsection{Flatness}

To continue, we check first whether the system (5) is flat. Since our model is control-affine and has 3 states and 2 inputs, then, by Theorem 2 , verifying flatness becomes relatively easy. Compute the sequence $\mathcal{H}_{k}$ of vector spaces of 1 -forms:

$$
\begin{aligned}
\mathcal{H}_{0}= & \operatorname{span}_{\mathcal{K}}\left\{\mathrm{d} x_{1}, \mathrm{~d} x_{2}, \mathrm{~d} x_{3}, \mathrm{~d} u_{1}, \mathrm{~d} u_{2}\right\} \\
\mathcal{H}_{1}= & \operatorname{span}_{\mathcal{K}}\left\{\mathrm{d} x_{1}, \mathrm{~d} x_{2}, \mathrm{~d} x_{3}\right\} \\
\mathcal{H}_{2}= & \operatorname{span}_{\mathcal{K}}\left\{\alpha_{1}\left(W_{s}-x_{2}\right) \mathrm{d} x_{1}\right. \\
& \left.+\left(\alpha_{2} W_{s}-\alpha_{2} x_{2}+\alpha_{1}\left(x_{1}-x_{3}\right)\right) \mathrm{d} x_{2}\right\} \\
\mathcal{H}_{3}= & \{0\} .
\end{aligned}
$$

\section{Table 1}

Nomenclature

\begin{tabular}{c|l}
\hline Parameter & \multicolumn{1}{c}{ Physical description } \\
\hline$x_{1}$ & temperature of thermal space \\
\hline$x_{2}$ & humidity ratio of thermal space \\
\hline$x_{3}$ & temperature of supply air \\
\hline$u_{1}$ & volumetric flow rate of air \\
\hline$u_{2}$ & flow rate of chilled water \\
\hline$h_{w}$ & enthalpy of liquid water \\
\hline$W_{O}$ & humidity ratio of outdoor air \\
\hline$h_{f g}$ & enthalpy of water vapor \\
\hline$V_{h e}$ & volume of heat exchanger \\
\hline$W_{S}$ & humidity ratio of supply air \\
\hline$C_{p}$ & specific heat air \\
\hline$T_{O}$ & temperature of outdoor air \\
\hline$M_{O}$ & moisture load \\
\hline$Q_{O}$ & sensible heat load \\
\hline$V_{S}$ & volume of thermal space \\
\hline$\rho$ & air mass density \\
\hline
\end{tabular}

Therefore, by Theorem 2, system (5) is flat or equivalently dynamic feedback linearizable. However, computation of the flat outputs is still needed, which, in general, is a difficult problem.

Here we use the decomposition procedure analogous to that, described in [13] for discrete-time systems, to derive the flat outputs for system (5). The decomposition results in a lower-order subsystem of (5), whose flatness property implies flatness of the system (5). Also, the flat outputs of the subsystem are the flat outputs of the original system (5). Thus, instead of finding the flat outputs of the system (5), we can find the flat outputs of the lower dimensional subsystem.

To find the decomposition, we are looking for a state transformation $z=\varphi(x)$ and an input transformation $\tilde{u}=c(u, x)$, such that the equations (1) are transformed into the form

$$
\begin{aligned}
& \dot{z}_{1}=\tilde{f}\left(z_{1}, z_{2}, \tilde{u}_{1}\right) \\
& \dot{z}_{2}=\bar{f}\left(z_{1}, z_{2}, \tilde{u}_{1}, \tilde{u}_{2}\right),
\end{aligned}
$$

where $z=\left(z_{1}, z_{2}\right)^{\mathrm{T}}, \tilde{u}=c(u, x)$ and $\operatorname{dim} z_{2}>0$. Then, one can, instead of system (1), study the flatness of a lower dimensional subsystem

$$
\dot{z}_{1}=\tilde{f}\left(z_{1}, z_{2}, \tilde{u}_{1}\right) \text {, }
$$

where $z_{2}$ and $\tilde{u}_{1}$ are considered as inputs. The necessary transformations can be computed based on the subspace $\mathcal{H}_{2}$. In fact, in the case of system (5), one does not need the input transformation, i.e., $\tilde{u}=u$, and $\mathrm{d} z_{1}$ is defined as the basis of a minimal integrable subspace containing $\mathcal{H}_{2}$, which is obviously $\operatorname{span}_{\mathcal{K}}\left\{\mathrm{d} x_{1}, \mathrm{~d} x_{2}\right\}$. Therefore, we continue with the subsystem

$$
\begin{aligned}
\dot{x}_{1}= & 60 \alpha_{1} u_{1}\left(x_{3}-x_{1}\right)-60 \alpha_{2} u_{1}\left(W_{s}-x_{2}\right) \\
& +\alpha_{3}\left(Q_{o}-h_{f g} M_{o}\right) \\
\dot{x}_{2}= & 60 \alpha_{1} u_{1}\left(W_{s}-x_{2}\right)+\alpha_{4} M_{o},
\end{aligned}
$$

where $u_{1}$ and $x_{3}$ are the input variables. Since the number of states in ( 7$)$ is equal to the number of inputs $(n=m)$ and the rank condition $\operatorname{rank} \mathcal{K} \frac{\partial f(\cdot)}{\partial u}=m$ is satisfied, one has $\mathcal{H}_{\infty}=\mathcal{H}_{2}=\{0\}$. Thus, by Theorem 1 , the system ( 7 ) is static state feedback linearizable with flat outputs $y_{1}=x_{1}$ and $y_{2}=x_{2}$, which are obtained by integration of $\mathcal{H}_{1}$. As shown in [13] for discrete-time systems, these flat outputs are also the flat outputs of system (5). Fortunately, these are also the variables we want to control, which makes the tracking control problem much easier to address. 


\subsection{Tracking Control}

To find the control input, which drives the system output $y$ to a desired value, one can utilize the relations (3). Namely, if we want the output $y$ to follow the trajectory $y_{\text {ref }}$, then, assuming that $y_{r e f}$ is $k$-times differentiable, one can compute the desired input from (3) by substituting $y_{\text {ref }}$ and its derivatives to $F_{u}$. Note that one should also ensure that the trajectory $y_{\text {ref }}$ passes the initial point $y(0)$.

We have shown that the temperature of the thermal space $y_{1}$ and the humidity ratio of thermal space $y_{2}$ are the flat outputs of system (5). To continue, we need to find the relations (3), which can be found from the following equations:

$$
\begin{aligned}
y_{1}= & x_{1} \\
y_{2}= & x_{2} \\
\dot{y}_{1}= & 60 \alpha_{1} u_{1}\left(x_{3}-x_{1}\right)-60 \alpha_{2} u_{1}\left(W_{s}-x_{2}\right) \\
& +\alpha_{3}\left(Q_{o}-h_{f g} M_{o}\right) \\
\dot{y}_{2}= & 60 \alpha_{1} u_{1}\left(W_{s}-x_{2}\right)+\alpha_{4} M_{o} \\
\ddot{y}_{1}= & 60 \alpha_{1} u_{1}\left(\alpha_{3}\left(M_{o} h_{f g}-Q_{o}\right)+60 \alpha_{2} u_{1}\left(W_{s}-x_{2}\right)\right. \\
& -60 \beta_{3} u_{1}\left(0.75 x_{2}+0.25 W_{o}-W_{s}\right) \\
& +15 \beta_{1} u_{1}\left(T_{o}-x_{1}\right)-6000 \beta_{2} u_{2} \\
& \left.-60 \alpha_{1} u_{1}\left(x_{3}-x_{1}\right)+60 \beta_{1} u_{1}\left(x_{1}-x_{3}\right)\right) \\
& +60 \alpha_{2} u_{1}\left(\alpha_{4} M_{o}+60 \alpha_{1} u_{1}\left(W_{s}-x_{2}\right)\right) \\
& -60 \alpha_{2} \dot{u}_{1}\left(W_{s}-x_{2}\right)+60 \alpha_{1}\left(x_{3}-x_{1}\right) \dot{u}_{1} .
\end{aligned}
$$

The functions $F_{x}$ and $F_{u}$ in (3) are found by solving the equations (8) in $x$ and $u$ :

$$
\begin{aligned}
x_{1}= & y_{1} \\
x_{2}= & y_{2} \\
x_{3}= & \left(\dot{y}_{1}+\frac{\alpha_{2}}{\alpha_{1}}\left(\dot{y}_{2}-\alpha_{4} M_{o}\right)\right. \\
& \left.-\alpha_{3}\left(Q_{o}-h_{f g} M_{o}\right)\right) \frac{W_{s}-y_{2}}{\dot{y}_{2}-\alpha_{4} M_{o}}+y_{1} \\
u_{1}= & \frac{\dot{y}_{2}-\alpha_{4} M_{o}}{60 \alpha_{1}\left(W_{s}-y_{2}\right)} \\
u_{2}= & -\frac{1.667 \times 10^{-4}}{\alpha_{1} \beta_{2} u_{1}}\left(\alpha_{1} \alpha_{3} u_{1}\left(Q_{o}-M_{o} h_{f g}\right)\right. \\
& -\alpha_{2} u_{1}\left(\alpha_{4} M_{o}+60 \alpha_{1} u_{1}\left(W_{s}-y_{2}\right)\right) \\
& +60 \alpha_{1} \beta_{3} u_{1}^{2}\left(0.75 y_{2}+0.25 W_{o}-W_{s}\right) \\
& +\alpha_{2} \dot{u}_{1}\left(W_{s}-y_{2}\right)-60 \alpha_{1} \alpha_{2} u_{1}^{2}\left(W_{s}-y_{2}\right) \\
& -15 \alpha_{1} \beta_{1} u_{1}^{2}\left(T_{o}-y_{1}\right)-60 \alpha_{1} \beta_{1} u_{1}^{2}\left(y_{1}-x_{3}\right) \\
& -\alpha_{1} \dot{u}_{1}\left(x_{3}-y_{1}\right)+60 \alpha_{1}^{2} u_{1}^{2}\left(x_{3}-y_{1}\right) \\
& \left.+1.667 \times 10^{-2} \ddot{y}_{1}\right) .
\end{aligned}
$$

Note that we have not replaced $u_{1}, \dot{u}_{1}$ and $x_{3}$ in the expression of $u_{2}$ in (9) for the reason to have visually compact expressions.
Our goal is to obtain constant values $r_{1}$ and $r_{2}$ for the temperature and humidity ratio of thermal space, respectively. To do that, the reference trajectories are chosen as

$$
\begin{aligned}
& y_{1 r}=\left(y_{1}(0)-r_{1}\right) e^{-a t}+r_{1} \\
& y_{2 r}=\left(y_{2}(0)-r_{2}\right) e^{-a t}+r_{2} .
\end{aligned}
$$

\section{Table 2}

Numerical values for system parameters

\begin{tabular}{c|c|c}
\hline Parameter & Value & Unit \\
\hline$h w$ & 340.78 & Btu/lb \\
\hline$W_{O}$ & 0.018 & $l b / l b$ \\
\hline$h_{f g}$ & 1078.25 & $B t u / l b$ \\
\hline$V_{h e}$ & 60.75 & $f t^{3}$ \\
\hline$W_{S}$ & 0.007 & $l b / l b$ \\
\hline$C_{p}$ & 0.24 & $B t u / l b^{\circ} F$ \\
\hline$T_{O}$ & 85 & ${ }^{\circ} F$ \\
\hline$M_{O}$ & 166.06 & $l b / h o u r$ \\
\hline$Q_{O}$ & 289897.52 & $B t u / h o u r$ \\
\hline$V_{S}$ & 58464 & $f t^{3}$ \\
\hline$\rho$ & 0.074 & $l b / f t^{3}$ \\
\hline
\end{tabular}

The reference trajectories (10) pass the initial points, are two times differentiable and converge asymptotically to the values $r_{1}$ and $r_{2}$, respectively. Thus, $y_{1 r}$ and $y_{2 r}$ in (10) are useful for achieving our goals. Since in (9) one has derivatives of $y$ up to the order 2 , we need to compute the first and second derivatives of $y_{1 r}$ and $y_{2 r}$ :

$$
\begin{aligned}
& \dot{y}_{i r}=-a\left(y_{i}(0)-r_{i}\right) e^{-a t} \\
& \ddot{y}_{i r}=a^{2}\left(y_{i}(0)-r_{i}\right) e^{-a t}
\end{aligned}
$$

for $i=1,2$. Substituting $y_{i r}, i=1,2$, and their derivatives to the expressions of $u_{1}$ and $u_{2}$ in (9) results in a feedforward control that yields the trajectories (10) for $y_{1}=x_{1}$ and $y_{2}=x_{2}$.

\section{Simulation Results}

The numerical values of all the system parameters used in the simulations are given in Table 2 . The same values have been used also in [12], which makes comparisons with those results possible. In all the simulations the initial values were selected as: $x_{1}(0)=76^{\circ} F$, 
$x_{2}(0)=0.021 l b / l b$ and $x_{3}(0)=55^{\circ} \mathrm{F}$. The desired values for the temperature and humidity ratio of thermal space are ${ }^{r} 71^{\circ} \mathrm{F}$ and $0.0092 l b / l b$, respectively.

The controller is computed by substituting the reference trajectories, given by (10), and their derivatives, given by (11), to the expressions of $u_{1}$ and $u_{2}$ in (9). By theory, this controller yields the trajectories (10) for the temperature $y_{1}$ and humidity ratio $y_{2}$ of thermal space. Theory is confirmed by simulations seen in Fig. 2 for three different values of the parameter $a$ in (10).

It is also interesting to see, how the respective system inputs change over time, see Fig. 3. As expected, if we want the temperature and humidity ratio to converge faster to the desired values, then the respective inputs have bigger values, which refers to bigger energy usage. The balance between the two should be achieved by choosing the parameter $a$ appropriately.

In the papers $[5,18,12]$ the input signals $u_{1}$ and $u_{2}$ in (5) are implemented by using liquid valves and therefore the valve dynamics, given by the transfer functions

Figure 2

Outputs $y_{1}$ and $y_{2}$ for different values of parameter $a$

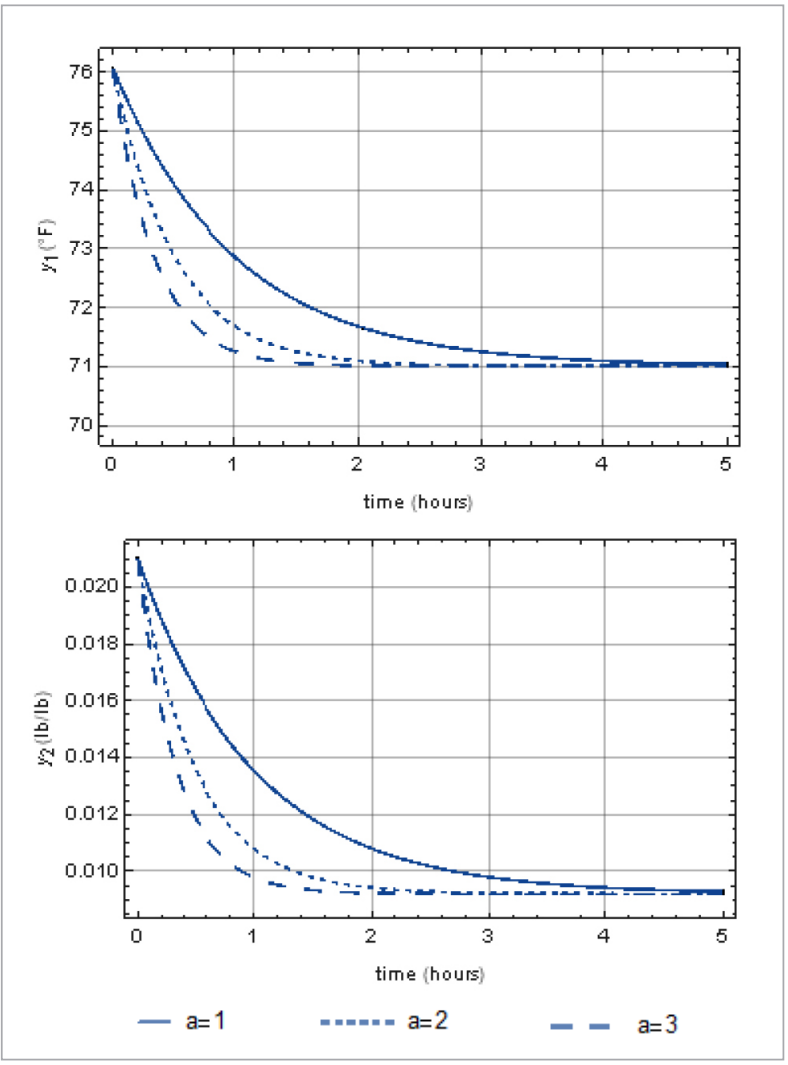

$$
u_{1}=\frac{k_{1}}{1+\tau_{1} s} v_{1} \quad u_{2}=\frac{k_{2}}{1+\tau_{2} s} v_{2}
$$

is added to the model (5). In the extended system (5), (12) $u=\left(u_{1}, u_{2}\right)^{\mathrm{T}}$ is the control input applied to the plant, $v=\left(v_{1}, v_{2}\right)^{\mathrm{T}}$ is the input applied to the actuator and $k_{1}, k_{2}, \tau_{1}$ and $\tau_{2}$ are constants. Similar flatness-based control as for system (5) can be carried out for the extended system (5), (12). In fact, since $x_{1}$ and $x_{2}$ are still the flat outputs of the extended system, then the only difference compared to the system (5), is that in (3) there is an additional relation $F_{v}$, which describes how the variables $v$ are expressed in terms of the flat outputs and their derivatives.

Making the simulations with the same conditions as above and taking $k_{1}=k_{2}=5, \tau_{1}=\tau_{2}=0.008$ yields the same results for the system outputs (see Fig. 2) and inputs $u$ (see Fig. 3). The values of the actuator inputs $v$ can be seen in Fig. 4. Although the simulations are

Figure 3

Input values, that drive the outputs into desired values

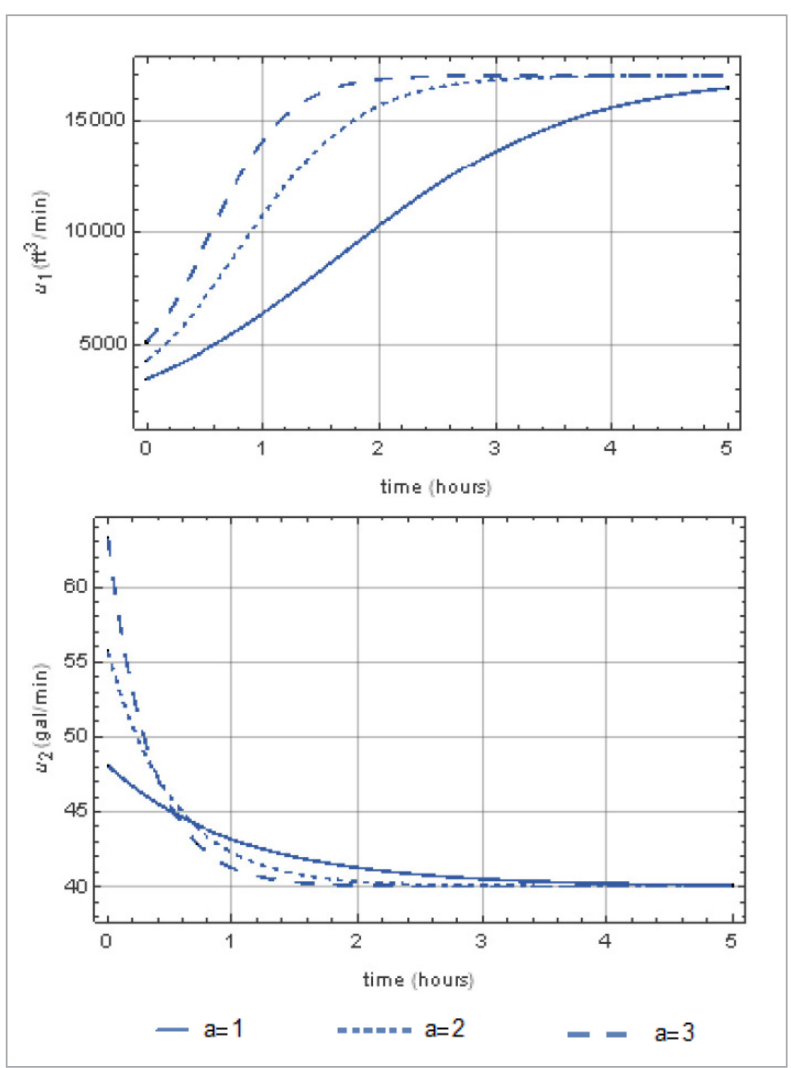




\section{Figure 4}

Actuator input values for the extended system
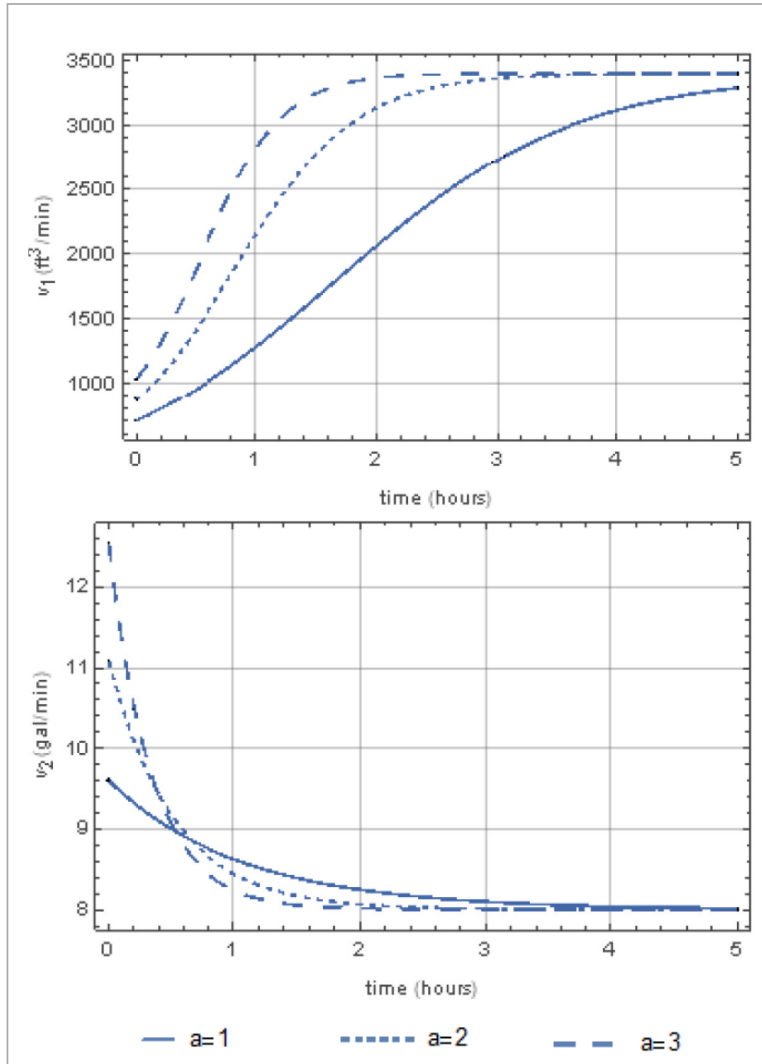

slightly different, the values of the inputs $v$ required to achieve the desired room temperature are considerably smaller than those in [18]. Compared to the results of [12] in our simulations the outputs converge to the desired values similarly, but as mentioned in the Introduction, our controller does not need the measurements or the estimations of the system states, whereas the controller in [12] does.

\section{Conclusions}

It was shown that a particular model of a HVAC system, studied in many other papers, is flat with flat outputs equal to the temperature and humidity ratio of thermal space. This fact was utilized to design a flatness based feedforward controller, which drives the system outputs (flat outputs) to the desired values. A big advantage compared to many other results is that our controller does not need the measurements or the estimations of the system states.

Flatness property has been used also in many other areas of control. For example, in the paper [7] a method was described, which combines the flatness formalism for trajectory generation with the nonlinear model predictive control (NMPC) for constraint handling. Thus, in the future studies it would be interesting to see, how the combination of flatness and NMPC can be used in controlling HVAC systems. Note that flatness can also be used to simplify the optimization problem in NMPC $[15,19]$. In this article, we have fixed the reference trajectory, but one may be able to use the NMPC to find an optimal trajectory.

\section{Acknowledgment}

The work done in this paper was supported by the Estonian Research Council grant PUT481.

\section{References}

1. Anderson, M., Buehner, M., Young, P., Hittle, D., Anderson, C., Tu, J., Hodgson, D. MIMO Robust Control for HVAC Systems. IEEE Transactions on Control Systems Technology, 2008, 16(3), 475-483. https://doi. org/10.1109/TCST.2007.903392

2. Aranda-Bricaire, E., Moog, C. H., Pomet, J. B. A Linear Algebraic Framework for Dynamic Feedback Linearization. IEEE Transactions on Automatic Control, 1995, 40(1), 127-132. https://doi.org/10.1109/9.362886
3. Argüello-Serrano, B., Vélez-Reyes, M. Nonlinear Control of a Heating, Ventilating and Air Conditioning System with Thermal Load Estimation. IEEE Transactions on Control Systems Technology, 1999, 7(1), 56-63. https://doi.org/10.1109/87.736752

4. Belikov, J., Kotta, Ü., Srinivasan, S., Kaldmäe, A., Halturina, K. On Exact Feedback Linearization of HVAC Systems. In Proceedings of the 2013 International Conference on Process Control, Strbske Pleso, Slovakia, 2013, 353-358. https://doi.org/10.1109/PC.2013.6581436 
5. Chiang, M.-L., Fu, L.-C. Hybrid System Based Adaptive Control for the Nonlinear HVAC System. In Proceedings of the 2006 American Control Conference, Minneapolis, USA, 2006, 5324-5329. https://doi.org/10.1109/ ACC.2006.1657569

6. Conte, G., Moog, C. H., Perdon, A. M. Algebraic Methods for Nonlinear Control Systems. Springer-Verlag, London, UK, 2007. https://doi.org/10.1007/978-1-84628595-0

7. De Dona, J. A., Suryawan, F., Seron, M. M., Lévine, J. A Flatness-Based Iterative Method for Reference Trajectory Generation in Constrained NMPC. In Nonlinear Model Predictive Control. Springer Berlin Heidelberg, 325-333, 2009. https://doi.org/10.1007/978-3-64201094-1_27

8. Ferreira, P. M., Silva, S. M., Ruano, A. E., Négrier, A. T., Conceicao, E. Z. E. Neural Network PMV Estimation for Model-Based Predictive Control of HVAC Systems. In IEEE World Congress on Computational Intelligence, Brisbane, Australia, 2012, 1-8. https://doi.org/10.1109/ IJCNN.2012.6252365

9. Fliess, M., Lévine, J., Martin, P., Rouchon, P. Flatness and Defect of Nonlinear Systems: Introductory Theory and Examples. International Journal of Control, 1995, 61(6), 1327-1361. https://doi. org/10.1080/00207179508921959

10. Fliess, M., Lévine, J., Martin, P., Rouchon, P. A Lie-Bäcklund Approach to Equivalence and Flatness of Nonlinear Systems. IEEE Transactions on Automatic Control, 1999, 44(5), 922-937. https://doi.org/10.1109/9.763209

11. Huaguang, Z., Cai, L. Decentralized Nonlinear Adaptive Control of an HVAC System. IEEE Transactions on Systems, Man, and Cybernetics, Part C (Applications and Reviews), 2002, 32(4), 493-498. https://doi. org/10.1109/TSMCC.2002.807271

12. Kang, C.-S., Park, J.-I., Park, M., Baek, J. Novel Modeling and Control Strategies for a HVAC System Including Carbon Dioxide Control. Energies, 2014, 7(6), 35993617. https://doi.org/10.3390/en7063599

13. Kolar, B., Kaldmäe, A., Schöberl, M., Kotta, Ü., Schlacher, K. Construction of Flat Outputs of Nonlinear Discrete-Time Systems in a Geometric and an Algebraic
Framework. In Proceedings of the 10th IFAC Symposium on Nonlinear Control Systems, Monterey, California, USA, 2016, 796-801. https://doi.org/10.1016/j. ifacol.2016.10.263

14. Kolar, B., Rams, H., Schlacher, K. Time-Optimal Flatness Based Control of a Gantry Crane. Control Engineering Practice, 2017, 60, 18-27. https://doi. org/10.1016/j.conengprac.2016.11.008

15. Murray, R. M., Hauser, J., Jadbabaie, A., Milam, M. B., Petit, N., Dunbar, W. B., Franz, R. Online Control Customization via Optimization-Based Control. In Software-Enabled Control: Information Technology for Dynamical Systems. Wiley-Interscience, 149-174, 2002.

16. Parisio, A., Fabietti, L., Molinari, M., Varagnolo, D., Johansson, K. H. Control of HVAC Systems via Scenario-Based Explicit MPC. In Proceedings of the 53rd IEEE Conference on Decision and Control, Los Angeles, USA, 2014, 5201-520\%. https://doi.org/10.1109/ CDC.2014.7040202

17. Rentel-Gómez, C., Vélez-Reyes, M. Decoupled Control of Temperature and Relative Humidity Using a Variable-Air-Volume HVAC System and Non-Interacting Control. In Proceedings of the 2001 IEEE International Conference on Control Applications, Mexico City, Mexico, 2001, 1147-1151. https://doi.org/10.1109/ CCA.2001.974026

18. Semsar-Kazerooni, E., Yazdanpanah, M. J., Lucas, C. Nonlinear Control and Disturbance Decoupling of HVAC Systems Using Feedback Linearization and Backstepping with Load Estimation. IEEE Transactions on Control Systems Technology, 2008, 16(5), 918929. https://doi.org/10.1109/TCST.2007.916344

19. Simon, D., Löfberg, J., Glad, T. Nonlinear Model Predictive Control Using Feedback Linearization and Local Inner Convex Constraint Approximations. In Proceedings of the 2013 European Control Conference, Zurich, Switzerland, 2013, 2056-2061.

20. Sira-Ramirez, H., Agrawal, S. K. Differentially Flat Systems. CRC Press, New York, 2004.

21. Tigrek, T., Dasgupta, S., Smith, T. F. Nonlinear Optimal Control of HVAC Systems. In Proceedings of the 15th IFAC World Congress, Barcelona, Spain, 2002, 149-154. 


\section{Summary / Santrauka}

This paper studies the flatness-based control of a nonlinear multi-input multi-output heating, ventilating and air conditioning (HVAC) system. First, a novel method for checking flatness property is used to verify that the given HVAC model is flat and that the flat outputs are the temperature and the humidity ratio of the thermal space. Since the flat outputs are also the variables, which one usually wants to control, it is relatively easy to construct a flatness-based feedforward control for the HVAC model. We define the appropriate trajectories for the flat outputs and then the controller is computed from the parametrization of system inputs in terms of flat outputs and their derivatives. The trajectories of flat outputs are chosen such that the temperature and the humidity ratio converge asymptotically from the initial values to the desired values. Simulations are made, which show the effectiveness of the approach.

Straipsnyje nagrinėjama plokštumu grịstos netiesinių daugybinès įeigos ir išeigos šildymo, ventiliavimo ir oro kondicionavimo (HVAC) sistemos kontrolè. Pirma, panaudojamas naujas plokštumo savybių tikrinimo metodas, skirtas patvirtinti, kad HVAC modelis yra plokščias ir kad plokščiosios išeigos yra šiluminès erdvès temperatūros ir drègmès santykis. Kadangi plokščiosios išeigos taip pat apima kintamuosius, kuriuos įprastai ir norima kontroliuoti, yra sąlyginai nesudètinga sukurti plokštumu grịstą HVAC modelio perdavimo pirmyn valdymą. Autoriai įvardina tinkamas plokščiųų išeigų trajektorijas, tuomet, atsižvelgdami į plokščiąsias išeigas ir jų išvestinius elementus, iš sistemos įeigų parametrizavimo apskaičiuoja valdiklį. Plokščiujų išeigų trajektorijos pasirinktos taip, kad temperatūros ir drègmès santykis asimptomiškai konverguotų iš pradinių verčių į norimas. Atliktos simuliacijos atskleidžia siūlomo modelio efektyvumą. 